\title{
Reactivity of Carbon Deposited on Nickel-Copper Alloy Catalysts from the Decomposition of Methane
}

The catalytic effect of $\mathrm{Ni}-\mathrm{Cu}$ alloys in many reactions has been the subject of a number of publications, including two reviews $(1,2)$. Some of these publications refer to supported alloys, and the influence of copper on their activity as catalysts (38 ). Recently, the authors studied the steam reforming and the decomposition of methane on silica-supported $\mathrm{Ni}-\mathrm{Cu}$ catalysts, to evaluate whether copper addition depresses the formation of carbon without affecting the main reaction (9).

It was found that, in the absence of steam, the carbon deposition rates depended both weakly (below 10 at.\% $\mathrm{Cu}$ ) and significantly (above 10 at.\% Cu) on the copper content. At very high copper concentrations (80 at.\%), a new carbon structure was observed in which various filaments of nearly amorphous carbon were attached to the same metallic particle. This "octopus" carbon could not be observed at lower copper concentrations, in which the usual "whisker" structure, consisting of filaments with a metallic particle at the top (10) predominated. For these concentrations, the carbon formation/gasification equilibrium in $\mathrm{CH}_{4}-\mathrm{H}_{2}$ mixtures was the same for the $\mathrm{Ni}-\mathrm{Cu}$ alloys as for pure nickel catalysts.

In order to evaluate the effect of the catalyst composition on the nature of the carbon deposits formed on it, and the reactivity of the latter towards hydrogen, a series of temperature-programmed reactions (TPR) was performed. Silica-supported Ni$\mathrm{Cu}$ catalysts, prepared by "dry" impregnation and characterized in the same way as in the previous study (9) were used. Carbon was deposited on them, from $\mathrm{CH}_{4}-\mathrm{H}_{2}$ mix tures in constant conditions $\left(850 \mathrm{~K}, P_{\mathrm{CH}_{4}}\right.$ $=13 \mathrm{kPa}, P_{\mathrm{CH}_{2}}=7 \mathrm{kPa}, \mathrm{N}_{2}$ as balance), in a reaction system consisting of a C.I. Electronics MK2B microbalance and associated flow reactor. Gasification thermograms were obtained by heating the carbon deposit at constant heating rate under a flow of hydrogen, using a Mark III Stanton Redcroft Temperature Programmer (11). The derivative thermogravimetric curves that yield information on the reactivity of the deposits are presented in Fig. 1 for the different alloy compositions.

In the figure, the "peak temperatures," $T_{\mathrm{p}}$, which correspond to the maxima in the rate of methane production, are characteristic of the reactivity of the different types of carbon in the deposit (12). As a general rule, a higher peak temperature corresponds to a carbon state of lower reactivity. Several of these states have been identified in carbon deposited from $\mathrm{C}_{2} \mathrm{H}_{4}$ on $\mathrm{Ni} / \mathrm{Al}_{2} \mathrm{O}_{3}$ (13). The $T_{\mathrm{p}}$ values obtained from Fig. 1 are summarized in Table 1 for the compositions studied.

From Fig. 1 and Table 1 it can be concluded that under the conditions used either one or two types of carbon can be identified for each catalyst (below and above 10 at.\% $\mathrm{Cu}$, respectively). For the pure nickel catalyst, the value of $T_{\mathrm{p}}$ is close to that reported by McCarty and co-workers (13) for the gasification of filamentous carbon deposited on nickel after exposure to ethylene at 773 and $873 \mathrm{~K}(875 \pm 20 \mathrm{~K})$. Similar work was done on deposits ex $\mathrm{C}_{2} \mathrm{H}_{6}$ formed on nickel and iron foils (11). The values of $T_{\mathrm{p}}$ obtained were 905 and $1030 \mathrm{~K}$, for nickel 


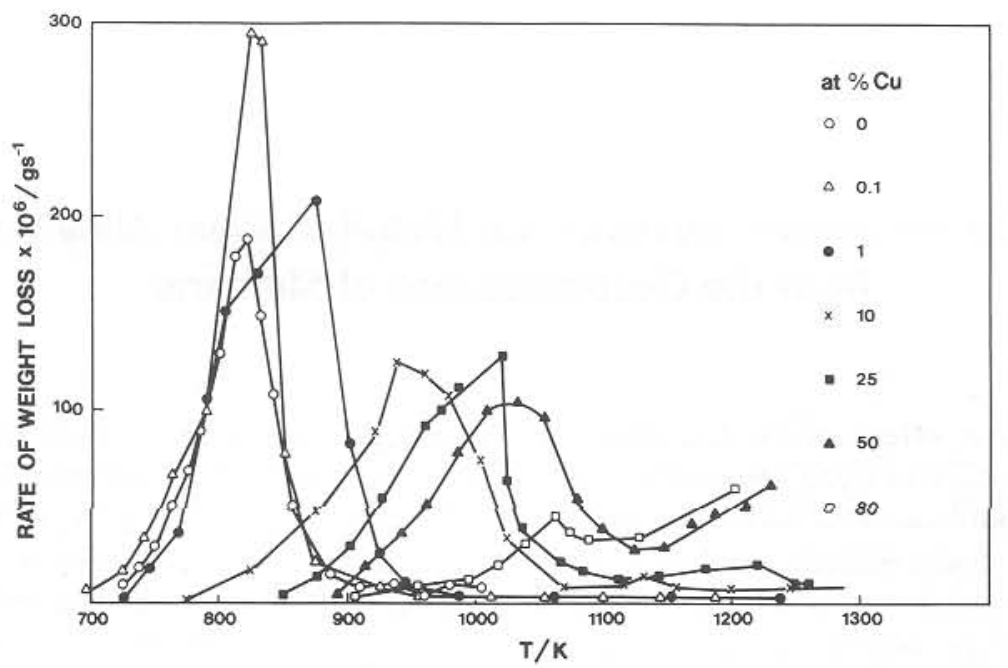

FIG. 1. Temperature-programmed gasification of carbon deposited on $\mathrm{Ni}-\mathrm{Cu}$ catalysts. Conditions: heating rate $=0.1 \mathrm{~K} \mathrm{~s}^{-1}, P_{\mathrm{H}_{2}}=50 \mathrm{kPa}, \mathrm{N}_{2}$ as balance. Total flow: ca. 0.6 mole h${ }^{-1}$. Catalysts: $20 \mathrm{wt} \%$ total nickel plus copper, nominal bulk copper concentrations in the metallic phase as indicated. Initial weight of carbon: 1.6 to $2.4 \mathrm{mg}$.

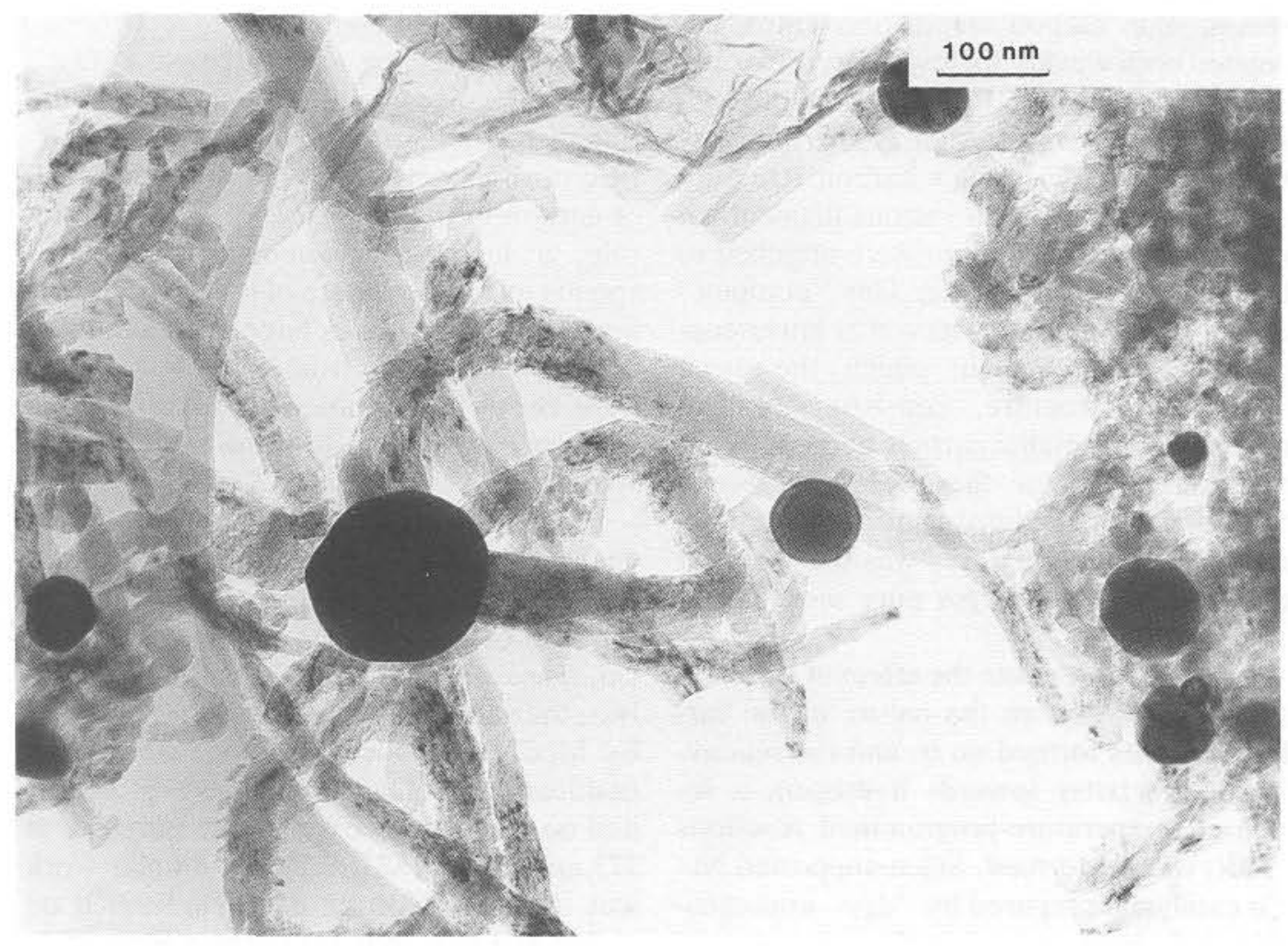

FIG. 2. Electron micrograph of the carbon deposited on 25 at.\% Cu catalyst ("octopus" carbon). 
TABLE 1

TPR Characterization of the Carbon Deposited ${ }^{a}$ on $\mathrm{Ni}-\mathrm{Cu} / \mathrm{SiO}_{2}$ Catalysts

\begin{tabular}{ccc}
\hline $\begin{array}{c}\text { At.\% of Cu in the } \\
\text { metallic phase }\end{array}$ & $T_{\mathbf{p}_{1}}(\mathrm{~K})$ & $T_{\mathrm{p}_{2}}(\mathrm{~K})$ \\
\hline 0 & 820 & - \\
0.1 & 825 & - \\
1 & 875 & - \\
10 & 935 & 1145 \\
25 & 1020 & $>1200$ \\
50 & 1030 & $>1240$ \\
80 & 1060 & $>1200$ \\
\hline
\end{tabular}

${ }^{a}$ Deposition temperature: $850 \mathrm{~K}$, carbon ex $-\mathrm{CH}_{4}$.

and iron, respectively. Previous electron microscopy observations indicated that most of the carbon formed on samples with less than 80 at.\% $\mathrm{Cu}$ was of filamentous whisker-type nature (9). Hence, it may be concluded that the $T_{\mathrm{p}_{1}}$ values measured for all the copper concentrations correspond to the gasification of this type of carbon. It is seen in Fig. 1 that the reactivity decreases with increasing copper content and that, above 10 at. $\% \mathrm{Cu}$, another type of carbon appears in the deposits in increasing amounts from 25 to 80 at. $\% \mathrm{Cu}$.

Inspection under the electron microscope of the deposit formed on the 25 at.\% $\mathrm{Cu}$ catalyst revealed considerable amounts of "octopus" carbon, similar to the carbon previously observed on the 80 at.\% Cu catalyst (9), with metallic particles whose diameters were two to three times larger than that of the filaments attached to them. A typical structure is represented in Fig. 2.

This observation suggests that "octopus" carbon may be responsible for the second peak present in the thermograms. The carbon in the filaments of this structure is observed to be much less ordered than that in the outer shell of the filaments of the "whisker" carbon and, consequently, $T_{\mathrm{p}}$ should be lower. However, in the "octopus" carbon, the metal should play a much lesser role in the gasification which can almost be considered noncatalytic. Thus, a higher $T_{\mathrm{p}}$ should be expected in this case. With the 80 at.\% catalyst, in which "octopus" carbon is known to predominate (9), the first peak is almost nonexistent. Although it is difficult to obtain with this catalyst a deposit large enough to allow for a proper TPR, it is evident that the form of carbon corresponding to $T_{\mathrm{p} 2}$ is the dominant one.

It can be concluded that "octopus" carbon may be present in all deposits formed on $\mathrm{Ni}-\mathrm{Cu} / \mathrm{SiO}_{2}$ catalysts with more than 10 at.\% $\mathrm{Cu}$ in the metallic phase, together with "whisker" carbon, i.e., on the catalysts for which the metal particle surfaces are strongly enriched in copper (9), and it predominates at 80 at.\% $\mathrm{Cu}$. This may be related to the change from a type I to a type II reaction according to the classification of Ponec (2) observed in the deposition from $\mathrm{CH}_{4}$ above 10 at. $\% \mathrm{Cu}(9)$.

\section{ACKNOWLEDGMENTS}

The authors are indebted to Dr. J. L. Figueiredo for providing the experimental facilities for the deposition and TPR-studies. This work was carried out under NATO Research Grant 406/84.

\section{REFERENCES}

1. Khulbe, K. C., and Mann, R. S., Catal. Rev.-Sci. Eng. 24, 311 (1982).

2. Ponec, V., Int. J. Quantum Chem. 12, Suppl. 2, 1 (1977).

3. Bajpai, P. K., Bakhshi, N. N., Dan-Chu, L., and Mathews, J. F., Canad. J. Chem. Eng. 60, 613 (1982).

4. Barcicki, J., Nazimek, D., Grezegorczyk, W., Borowiecki, T., and Denis, A., Pol. J. Chem. 55, 1839 (1981).

5. Vass, M. I., and Contescu, C. R., Rev. Roum. Chim. 25, 55 (1980).

6. Luyten, L. J. M., van Eck, M., van Grondelle, J., and van Hooff, J. H. C., J. Phys. Chem. 82, 2000 (1978).

7. Dalmon, J. A., and Martin, G. A., J. Catal. 75, 233 (1982).

8. Cale, T. S., and Richardson, J. T., J. Catal. 94, 289 (1985).

9. Bernardo, C. A., Alstrup, I., and Rostrup-Nielsen, J. R., J. Catal. 96, 517 (1985). 
10. Baker, R. T. K., Barber, M. A., Harris, P. S., Feates, F. S., and Waite, R. J., J. Catal. 26, 51 (1972).

11. Figueiredo, J. L., Bernardo, C. A., and Orfāo, J. J. M., "Carbon and Coal Gasification: Science and Technology," NATO ASI Series E, No. 165, p. 269. Nijhoff, Dordrecht, 1986.

12. McCarty, J. G., and Wise, H., J. Catal. 57, 406 (1979).

13. McCarty, J. G., Hou. P. Y., Sheridan, D., and Wise, H., Amer. Chem. Soc.-Symp. Ser. 202, 253 (1982).

\section{Teresa Tavares \\ C. A. Bernardo}

Centro de Quimica Pura

e Aplicada (INIC)

Universidade do Minho

4719 Braga Codex

Portugal

I. Alstrup

J. R. RosTRUP-NIELSEN

Haldor Topsфe Research Laboratories DK-2800 Lyngby

Denmark

Received February 4, 1986 